She was therefore helped to the hospital, and admitted to the labour ward about 5 A.M. The Sub-Asst. Surgeon and Matron were at once sent for, but before either of them could arrive, and at a moment when (as it happened) only a female ward coolie was in the room, the woman gave birth to the fotus to be subsequently described. According to the ward coolie's statement, the head presented at the vaginal orifice first, then the "hands" were born, and then the rest came away, bent up, "like a ball of flesh."

The ward coolie thereupon went for assistance, and at that moment the Sub-Asst. Surgeon arrived (i.e., about $5 \cdot 30$ A.M.) $\mathrm{He}$ at once recognised that the fotus was to all intents and purposes a puppy, and, finding that it was not attached to the mother, enquired if the placenta had come away. Hearing that it had not, he waited a little, and then (as there was no sign of bleeding), took the fœtus to the Matron, and sent me a message informing me of the abnormal birth. IVhen he left the ward, there was' no dis. charge of any kind from the vagina, nor was the bed soiled. On his return, he found the abdomen flat and flaccid and could not feel the uterus.

I examined the woman about 10 A.M., and found the abdomen as stated above. There was no pain on pressure, and the uterus could not be palpated. There was no discharge from the vagina, and no placenta had come away. The breasts showed no sigus of lactation.

Vaginal examination showed the mucous membrane to be of the pinkish colour normal for the non-pregnant state, and the uterus was also of a normal non-pregnant shape, not more than 3 inches long. It was retroverted. The external os admitted one finger up, but the internal os was tightly closed, and resisted very firm pressure. There was no sanious discharge. I ordered diapers to be put on and carefully preserved. These showed a slight discolouration for 3 days, but this could be accounted for by the somewhat severe attempt to force the cervix open.

The fretus exactly resembled a new born puppy, which had had the whole of its skin,-with the exception of its four paws, ears, and nose-carefully removed. It was about 6 inches long and not decomposed. The abdomen had been ruptured and the intestines were protruding. Only the stump of its tail was remaining, there was no umbilical cord. The head was slightly damaged and blood-stained.

The above case suggests 5 solutions, and I leave it to your readers to decide upon the particular one they prefer.

1. That the woman was pregnant by a man, and that the result was the monster shown.

2. That she was pregnant by a dgg, and that the result was the monster shown.

3. That she had been pregnant, had procured an abortion, and substituted the puppy fotus for her own.

4. That she was not pregnant, but did the whole thing out of a desire to secure an easy time for herself and give the authorities trouble.

5. Hysteria, pure and simple.

None of these theories can be fully explained ; the woman herself states that she believed she was pregnant by her husband, and can give no explanation of the pregnard result.

Perhaps some of your readers can citc instances similar to theories 1 and 2. Personally I have never read of any anthenticated case. The possibility of hysteria cannot be dismissed, but is contra-indicated by her general demeanour. and the lack of any exciting cause. Also, it is doubtful if any hysteria in an Indian woman would take the form of introducing a carefully prepared puppy into her vagina to complete the illusion of pregnancy.

As regards 3, the symptoms in favour of pregnancy are more than counterbalanced by those are several professional abortionists in the jail so that there would be no difficulty from that point of view. Nor would it be difficult to procure a new born puppy; the jail is bounded on two sides by the sea, and dogs are constantly entering the jail at low tide and seeking suitable homes for their offspring under the wooden barracks. Also it is not uncommon for a dead puppy to be washed up by the incoming tide.

If the woman was pregnant, as she stated, by her husband. there appears to be no reason for procuring an abortion. If by another man, there might be some reason for desiring an abortion, but not for substituting a puppy for the foetus.

On the whole, theory 4 seems the most likely, and the woman was certainly successful in securing 6 months light lahour for herself.

The importance of the case lies in its legal aspect. Should she be treated medically for hysteria, or be tried for a criminal offence? The difference to the woman is very marked : $\$ 377$, I. P. C., lays down a punishment of transportation for life or 10 years with or without fine for unnatural offence ; $\$ 315$, I. P. C. gives 10 years with or without fine for criminal abortion: the Andaman and Nicobar Manual allows a maximum punishment of 2 years " Refractory dress" and "Haircropping," if the case is treated as a jail offence. But if it is all due to hysteria, "medical observation" is the worst that could happen to her.
The case has by this time been dealt with, but it may interest others to come to a conclusion for themselves; nor would the writer be averse to hearing the result of their cogitations.

PORT BlaIR, $\quad$ F. A. BARKER, CAPT., I. M.S., Supdt., Jails \& Civil Surgeon.

\section{"A CHANGE OF TITLE."}

T'o The Editor of "The Indian Madical GazetTe."

DEAR SIR,-I shall be obliged if you will please note that on July 1st the title of the Sleeping Sickness Burean was changed to the Tropical Diseases Bureau and the offices were moved to the Imperial Institute. All communications and exchanges of publications intended for the Bureau should now therefore be addressed to-

The Director.

Tropical Diseases Bureau

Imperial Institute London, S. W.

In October next the Sleeping. Sickness and Kaia Azar Eulletins which are sent to you in exchange for the Indian Medical Gazetle, will give place to the Tropical Diseases Bulletin, in which will be publisherl summaries of all the current literature of T'ropical and Sub-tropical diseases. A quarterly Tropical Veterinary Bulletin also will be issued by the Bureau.

\section{Yours faithfully, \\ A. G. BAGSHA ive,} Director.

\section{THERAPEUTIC NOTES.}

\section{TANNALBIN IN THE GERMAN ARMY.}

SPECIAL recognition has lately been bestowed on the diar rhoea specific--Tannalbin. According to the statement of the German Military Medical Journal (No. 8, 1912), the IVar Office has directed that a stock of tablets of the original preparation Tannalbin-Knoll should always be kept at the sanitary depôts of the German army.

This remarkable distinction conferred by an authority accustomed to critical examination, and compelled to adopt extreme economy in the ordering of drugs, shows that the standpoint of the commission for the German Pharmacopeia (5th Edition) has been followed, who specially indicite that only the original preparation of Tannalbin should be employ. ed, in contrast to the usual custom.

\section{THE MEDICAL SUPPLY ASSOCIATION.}

THE Medical Supply Association write that, owing to the great increase in their business they have had to build very much larger premises for themselves at 167 to 173 , Gray's Inn Road, London. They are always glad to receive visits from members of the Indian Medical Profession visiting Englan and to give ocular demunstration of the advances niade in apparatus. The reputation of the Medical Supply Association is well known hoth for reliability and moderation in price. Besides the general medical supplies for which they are well known, the company desire it to be known that they specialize in Electrical Work in X-Ray Apparatus, etc.

'TABLOID' HYPODERMIC ' ERGAMINE' 0.001 gm.

The latest addition to the list of 'Tabloid' Hypodermic products issued by Messrs. Burroughs, Wellcome \& Co., is 'Tabloid Hypodermic 'Ergamine' 0001 gm. 'Ergamine' is a recently isolated active principle of ergot, with a marked action on the uterus. The most important pharmacological action of 'Erganine' is as a stimulant of plain muscle this action being particularly conspicuous in the case of the uterus, which responds to mere traces of this poient sub stance. Therapeutically, 'Ergamine' is indicated when prompt contraction of the uterus is desired, as in cases of post-partum hamorrhage. It is introduced for clinical trial and the dose suggested is one milligramme repeated with great caution.

\section{'TABLOID' UPHTHALMIC PHYSOSTIGMINE SALICYLATE, GR. $1 / 4000$.}

\section{'TABLOID' OPHTHALMIC PILOCARPINE NITRATE, GR. 1/3000.}

Two new 'Tabloid' Ophthalmic products have been added to their list by Messrs. Burroughs, Wellcome \& Co. These are 